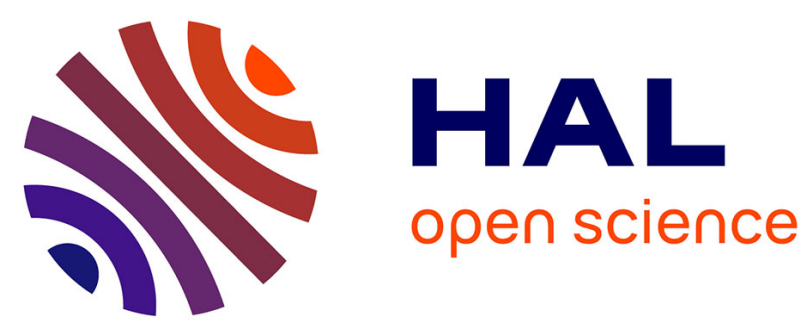

\title{
How Web Banner Designers Work: The Role of Internal Dialogues, Self-Evaluations, and Implicit Communication Theories
}

Didier Courbet, Marie-Pierre Fourquet-Courbet, Marc Vanhuele

\section{> To cite this version:}

Didier Courbet, Marie-Pierre Fourquet-Courbet, Marc Vanhuele. How Web Banner Designers Work: The Role of Internal Dialogues, Self-Evaluations, and Implicit Communication Theories. Journal of Advertising Research, 2007, 47 (2), pp.217-229. sic_00288393

\section{HAL Id: sic_00288393 \\ https://archivesic.ccsd.cnrs.fr/sic_00288393}

Submitted on 21 Jun 2008

HAL is a multi-disciplinary open access archive for the deposit and dissemination of scientific research documents, whether they are published or not. The documents may come from teaching and research institutions in France or abroad, or from public or private research centers.
L'archive ouverte pluridisciplinaire HAL, est destinée au dépôt et à la diffusion de documents scientifiques de niveau recherche, publiés ou non, émanant des établissements d'enseignement et de recherche français ou étrangers, des laboratoires publics ou privés. 


\section{How Web Banner Designers Work: The Role of Internal Dialogues, Self-Evaluations, and Implicit Communication Theories}

\section{MARIE-PIERRE FOURQUET-COURBET \\ University of Avignon, France \\ marie-pierre.fourquet@ \\ univ-avignon.fr}

\section{DIDIER COURBET}

University of

Nice-Sophia Antipolis,

France

dcourbet@unice.fr

\section{MARC VANHUELE}

HEC School of

Management, Paris,

France

vanhuele@hec.fr
This research was supported by the Centre National de la Recherche Scientifique (CNRSFrance), program "CognitiqueSociété de l'information."

In-depth interviews with web banner designers, combined with retrospective protocols, reveal implicit theories of the communication process that they apply during their creation process. These theories take the form of reactions of imaginary audiences with whom web banner designers engage in imaginary dialogues. The dialogues reveal the evaluation standards held by internet users, advertisers, and different colleagues.

Creative Communication Designers work with little or no support from formal theories of communication, but Kover (1995) shows that copywriters nevertheless share implicit theories about the functioning of communication that lack a scientific foundation but that people use to explain reality. They are implicit because the people who hold them are not necessarily aware of them and often cannot express them in a precise way (Furnham, 1990; Schneider, 1973). Kover elicits implicit theories through open interviews with copywriters and shows that the theories operate within the context of an internal dialogue between the creative person and an imaginary communication recipient, during which the creator tests potential messages on the virtual audience and refines them on the basis of the imaginary feedback obtained. This process continues iteratively until the designer achieves an emotional agreement. Whereas Kover's study is based on interviews with copywriters from traditional advertising agencies, we consider the extent to which his findings might apply to the production process of another group of communication professionals: creators of web banners.

Several reasons exist to doubt the applicability of Kover's (1995) findings to web banner designers. At a theoretical level, the notion of implicit theories stems from Moscovici's (1984) work on the social interpretations shared by a group, but such representations may not yet exist in the web designer world for two reasons. First, the business is young and may not have a strongly developed culture or set of processes to help newcomers assimilate. Second, web banner designers are a very heterogeneous group, including computer experts, graphic designers, traditional advertising creative personnel, and so forth. At a more practical level, designing web banners involves different cognitive processes than those associated with copywriting, as well as different sensory-motor actions, because it occurs on the computer and therefore may depend more on trial-and-error cycles than copywriting does.

In addition to examining whether implicit theories and internal dialogues are part of the web banner creation process, we examine how these two elements integrate in the actual creative process. Recent work (El-Murad and West, 2004; Lonergan, Scott, and Mumford, 2004; Mumford, 2003) outlines the steps of the creative process, which may or may not map onto Kover's (1995) internal dialogue idea. Does a creative process correspond to one long dialogue or a series of short ones with interruptions? Is the dialogue with one imaginary viewer or several?

Our project therefore has clear implications for different types of practitioners. Manuals about web advertising (e.g., Adams, 2003; Zeff and Aronson, 1999) discuss the results of the creative process, but rarely the process itself. In a professional context, most designers remain secretive about their working methods, so web banner creators may find that our work stimulates their own productivity, because they can discover how their colleagues work and reflect on their own work 
processes. Our study also could help advertising executives and even advertisers develop better working relationships with creative personnel through a better understanding of work methods and the mental models they hold of their own work.

In the next section, we provide an overview of recent frameworks describing the operation of creative processes in advertising. Subsequently, we describe the methodology of our study. The results appear in three different sections: In the first section, we show that Kover's (1995) implicit theories apply to web banner creation and that internal dialogues take place during the different phases of the creative process. In the next two sections, we present the key differences between our results and previous work by describing how our informants engage in dialogues with not one but five imaginary people and showing that idea evaluations, which typically appear in theories of creativity as the end phase of the creative process, actually exist during each of the creative steps.

\section{CREATIVE PROCESSES IN THE PRODUCTION OF ADVERTISING}

Prior research on creative thinking agrees that it involves some form of problem solving through generating novel and pertinent insights (Sternberg and Lubart, 1991) and proposes several models of creativity, often based on similar ideas, but that use different terminology (see Johar, Holbrook, and Stern, 2001; Mumford, 2003). In their review of the trends in creative research in an advertising context, ElMurad and West (2004) distinguish three primary theories. According to Kris's (1952) primary process cognition, a person switches between two types of processes: dreaming in a quasi-hypnotic state and reasoning in an abstract and logical way. Creative people switch easily between the two processes, using the first to discover new combinations of mental elements and the second to elaborate these newly discovered combinations. The theory of associative hierarchies (Mednick, 1962) pertains to people's abilities to make associations between previously unrelated facts; highly creative people make more such associations by using analogical transfer mechanisms. Finally, Mendelsohn's (1976) defocused attention theory takes as criteria the number of elements a person can keep in mind at one time, because more available elements allow for more original combinations, whereas focused attention makes fewer elements available.

The creative process itself also consists of different steps, though most authors refer to Wallas's (1926) four stages. The preparation stage consists of a series of preliminary analyses to solve a problem, followed by incubation, or a temporary withdrawal to let the project "stew." In the illumination stage, the person achieves a sudden insight, then examines it in the verification and evaluation stage. This last stage has received relatively little attention in the literature compared with creation stages.

Kover (1995, p. 599) observes that copywriters perceive the advertising communication process as consisting of two steps: "(1) breaking through to attract interest, and (2) delivering a message." Their engagement in internal dialogues helps them develop and mentally test messages that move the audience through these two steps. However, it is not clear how the processes that Kover describes fit with existing models of the creative process.

\section{METHODOLOGY}

Our objective is to gain an understanding of (1) the implicit representations and theories that web banner designers hold regarding the communication process in banner advertising and (2) the cognitive processes involved in web banner cre- ation and how they fit into existing theories about creative production. Because our objective has an exploratory nature, we undertake a qualitative research approach; Russ (2003) recommends this approach in particular for examining creative processes.

\section{Data collection}

We interviewed 31 French web banner designers for approximately an hour and a half each, using a face-to-face, semidirect format with open-ended questions. The interviewer asked opening questions and helped informants develop a clear representation of their ideas in depth through reformulations, relaunched questions, listening signals, the use of silence, and so forth. We combine this type of interview with retrospective protocols on the creation process (Reis and Gable, 2000), during which designers demonstrated their creations on a computer screen and explained step-by-step how they had developed them by thinking out loud. We used an interview guide inspired by Kover (1995) for the first five interviews, then complemented it to include coverage of the creative process (see the Appendix).

For our sample selection (see Table 1), we attempted to maximize the diversity of informant profiles in terms of work environment (advertising agency, internetoriented agency, freelance), size of the organization (small, average, large), geographical location (Paris area, provinces), level of education (self-taught, higher education in computer graphics, advertising), and age. The hermeneutic perspective we use for the analysis zooms in on commonalities in responses across respondents, not their differences (see Young, 2000).

\section{Interpretation}

Through our analysis, we attempt to identify shared views about the creative 
TABLE 1

\section{Informant Characteristics}

Advertising/communication agency: 11
Web agency: 9
Graphic design: 8
Other: 3
Paris region: 4
Provinces: 27
Freelance: 4
Less than 10 employees: 17
More than 20 employees: 10
Web design: 4
Graphic computer design: 4
Computer systems: 5
Traditional advertising: 10
Traditional graphical design: 6
Other: 2

process. After we filtered out irrelevant information, two coders independently analyzed the interview transcripts (1,203 responses, reactions, and remarks by the respondents 56,780 words) using the content analysis (Spiggle, 1994). After a first reading of all the transcripts, the coders assigned the text data to mutually exclusive categories that represent themes and subthemes, according to the methodology proposed by Weber (1990). We evaluate, on the one hand, the relative importance of each theme and subtheme compared with the entire corpus and, on the other hand, the importance of each subtheme compared with the topic to which it is attached. Intercoder agreement regarding themes is 85 percent, and disagreements were resolved after discussion. We achieved the saturation point (Glaser and Strauss, 1967) for the analysis at the 25th interview. From the 26th interview onward, we uncovered no new information.

\section{IMPLICIT THEORIES}

A specific characteristic of web banners, compared with standard advertisements, is their drive to generate clickthroughs to the website of the advertised brand (Chandon, Chtourou, and Fortin, 2003). Although their communication objectives differ from those of copywriters, web banner designers nevertheless maintain an implicit theory about the communication process that includes the same two steps discovered by Kover (1995) for traditional advertising; namely, they distinguish the challenges of drawing attention from those of delivering the message. Similar to advertising copywriters, banner designers represent their audience as individual persons with whom they engage in a dialogue.
To draw the attention of net surfers (first stage), designers rely on a mix of visual (animation, flickering, alternating moving and motionless elements, contrasts in colors, forms, and type) and semantic techniques (Kover, 1995). The communication rules that designers refer to seem to have a universal character, in that they apply in all situations and for all audiences and products (e.g., "flickering attracts the viewer's attention").

Some designers try to shock net surfers to get their attention, such as with a specific graphic atmosphere or the use of codes that are out of touch with the semantic universe of the product, but most use traditional approaches (originality, playfulness, teasing) to generate trust and signal to the receiver that visiting the advertiser's website will not be a waste of time. Their objective also often centers on generating positive emotions to make the receiver more open to the message itself. One informant expressed this very idea:

I make highly interactive banners with a message that changes when the viewer uses the mouse to move the cursor on the banner. Letting the user play makes him eager to know more about the brand behind the banner.

Once the imaginary recipient has allotted attention to the message, the designer tries to make him or her understand the content (second stage). To cause the viewer to progress through this stage successfully, the message must be simple on a formal level (e.g., appropriate typography, such as Arial font) and explicit on the semantic level (coherence between text and image). Despite the significant amounts of iconicity of advertising on the internet, according to our informants, consumer understanding occurs primarily because of the text: 


\section{The communication rules that designers refer to seem to}

\section{have a universal character, in that they apply in all situ-}

ations and for all audiences and products.

Because of the long download time, we cannot make beautiful commercials for the internet yet. The images in banners remain rather basic. It is therefore the text that communicates the message.

Once they understand the message, internet users move to the third stage, according to our informants: memorization of the message. To facilitate memorization, designers emphasize the key elements of the message (e.g., colors that are easily remembered, visual shifts, funny images). These elements get repeated in both the same and different banner advertisements, but there seems to be a threshold of maximum repetition that must not be crossed to avoid obstructing the viewer's surfing or psychological rejection of the brand.

Web banner designers are either more optimistic or more pessimistic about the impact of their work than were Kover's (1995) copywriters. Most of our informants think the internet has at least as much, if not more, influence than traditional advertising media (e.g., television, radio, press) because of its capacity to individualize communication and establish a privileged relationship with recipients by adapting messages to their psychological and demographic profiles:

Communication takes place in a more intimate setting than with other media. The individual is alone in front of the computer screen that stands physically close to him. This is the perfect medium for customer relationship management.
They also perceive the internet as a faster, more interactive, and richer multisensory medium than traditional media:

The advertiser often thinks that $a$ web surfer is a passive viewer. That's an error: because this person participates physically, thinks continuously before moving the mouse around. Watching, listening, feeling, the posture before the screen, they all make the internet a multisensory medium.

These designers sometimes appear to have an exaggerated opinion of the power of their creations, because they ignore other factors that determine banner success (e.g., product positioning, attractiveness of the offer, media plan). Thanks to the "feedback" that the internet allows (number of clicks, sales, site traffic), the designer can quickly assess the quality of the banner advertisements he or she created and modify them accordingly.

Some designers, however, consider web banners' influence weak. According to them, because the internet surfer is cognitively more "active" than recipients of traditional media, he or she also has greater ability to circumvent advertising. This avoidance stimulates the use of more intrusive forms of web advertising (e.g., pop-ups) that are considered potentially harmful for the advertiser, because they obstruct the web navigation and thereby cause net surfers to seek consciously to avoid them. In addition, as the recipient gets more experienced, he or she becomes accustomed to banner advertising, whose impact thus decreases.

\section{MULTIPLE DIALOGUES}

Our analysis of the interviews shows that, similar to copywriters, web banner designers "hear" intrapsychic voices and dialogue with them in working memory. Informants spontaneously mentioned the existence of these voices, not as a result of suggestive questioning by the interviewers. All their imaginary interaction processes follow the direction of a voice that represents the designer's ego during creation. According to Kover (1995), when a copywriter's ego interacts intrapsychically with "internalized others," a "psychic dissociation," if not a "creative trance," ensues. Our results corroborate Kover's description of an internal dialogue as coming close to "madness" or "automatic writing."

However, in contrast with Kover (1995), who refers to only one other actor (i.e., "an internalized target person," p. 601), the intrapsychic voices mentioned by our informants represent five distinct actors (in addition to the designer):

$I$ am in another world. I do not feel time passing and do not know where I am. The advertiser, the web surfer, and one or two colleagues join me in this world. I feel completely disconnected. We have a questionanswer session. On this basis, I can create banners very quickly. I close my eyes and see how the banner takes shape all by itself, as a result of the responses.

I try to see what each person would say; I check with each of them in turn.

The first voice the designer hears is that of a recipient surfing the internet who reacts to the message being created. If the designer knows the advertised product well, he or she becomes the referent. The designer then dissociates him- or herself into two separate entities and dialogues with the other self, who plays the role of 


\section{Web banner designers "hear" intrapsychic voices and}

\section{dialogue with them in working memory.}

a typical recipient of the web banner advertisement. When he or she knows little about the product, the designer creates a recipient using mental representations of a typical person. This dissociation also appears in Kover's (1995, p. 601) work. According to our respondents, this first voice might

tell me something like "this banner is interesting because it is the first time I see one like that," [then] I immediately check with the advertiser to have his opinion.

The second voice is that of the advertiser. The designer imagines what the advertiser would say about the designed banner advertisements on the basis of information received during briefings, the objectives of the campaign, and his or her knowledge of competitive banner advertising activity:

Suddenly, I hear the advertiser shouting that I am a no-good, that I do not understand what he wants. The web surfer [says] that the advertiser does not know what he is talking about and that he finds him funny.

The ego of the people interviewed also interacts with two imaginary colleagues. Kover, James, and Sonner (1997) demonstrate that professional colleagues serve as an important target audience for creative people; we confirm this role and show that colleagues are present in designers' minds during the creation process itself. The opinions of these two imaginary fellow members get mentally created from continuous monitoring of internet advertising.
The first colleague incarnates an excellent banner advertising designer who represents the standards and practices in the profession. Interaction with this fellow member of the design community provides an evaluation of the value of the choice options in the design:

My pal will say that this is just junk.

The second colleague knows all the latest fashions and recent trends in the field of advertising creation on the internet:

You are a real "has been" with this banner.

Finally, the fifth voice represents the aspirational self-image of the designer that he or she hopes others will hold about him or her and that will give him or her a unique position in the world of banner designers:

I want to leave my mark on each on my creations. In my mind I try to establish a compromise between what the advertiser has told me and my personal creative style; whenever possible, I try to make advertisements that are light, nice, or humorous.

Kover (1995, p. 602) describes how the dialogue "stops when the copywriter connects with the other, when the other and the copywriter communicate and the communication strikes an appropriate emotional cord in both," in which case, the tension of that dialogue is relieved. Our informants also feel the need to connect with several others and try to get positive reactions from all, which implies that compromises must be made and that tension usually remains, even if the best possible solution has been found:
It is rare that all those whom I imagine agree. But I have to make sure that at least three or four are not too frustrated.

\section{THE CREATIVE PROCESS}

How banner designers work

Banner designers perceive little difference between designs created by experience or by intuition. The process of self-observation that they spontaneously establish when engaging in their job does not involve verbalizing the rules, nor does it explain any processes in detail. Therefore, part of these processes likely is based on automatic, procedural know-how and created unconsciously, effortlessly, and without intentional control (Kirsner et al., 1998). Through repetition and intensive use, heuristics and procedures become automatic creation "practices" that are difficult to verbalize. However, designers do not depreciate their ignorance of their own reasoning; on the contrary, they regard it as valuable, a kind of artistic genius and talent:

Once I know the objectives I have to reach, things develop all by themselves in my head; I am unable to tell you how I do it; that's probably what we call "genius."

This talent is appreciated much more than scientific or academic knowledge. The results of the content analysis even show a certain depreciation of clearly thoughtout acts of creativity, in favor of intuitive acts based on a kind of creative illumination and synonymous with artistic talent:

What you learn in school are just the basics and the errors to avoid. You cannot acquire talent in school. It is about intuition. You are born with it or not.

At the same time, some stages of the creative processes seem more active and deliberate than the literature on creativity 


\section{Through repetition and intensive use, heuristics and}

\section{procedures become automatic creation "practices" that are difficult to verbalize.}

might suggest. Our informants use a range of well-developed techniques to search for an original association or develop one on the basis of preselected elements. In addition, they deliberately drop projects for some period of time, during which they search for exposure to other media (e.g., television, CD-ROMs) to "discover" analogies:

I look a lot at program sponsoring on television because these messages are similar to ours.

During or immediately after the intrapsychic verbal interactions, the designers enter a materialization phase in which they generate ideas through a very quick cognitive or sensory-motor process. Some designers see their creation first in mental imagery, whereas others prefer to put it down immediately, with paper and pencil or directly on the computer. Once visualized or graphically realized, the creators move to evaluate the resulting production.

\section{Continuous evaluations}

Our content analysis shows that a designer uses evaluation criteria based on five factors: (1) implicit theories about influence over the internet surfer, (2) the designer's perceptions of his or her personal creation style, (3) the knowledge he or she has acquired during previous creations that succeeded or failed, (4) current advertising trends and recent messages created by others, and (5) the perceived expectations of the advertiser. The correspondence between these factors and the internal voices we detailed in the previous section seems obvious. Implicit theories about the reactions of different partners during the imaginary dialogues intertwine with these evaluation criteria, and some dialogue partners clearly embody the criteria.

Contrary to the majority of academic work on the process of creativity, we find that the assessment process does not take place only at the end of the creative act. Instead, the designer self-evaluates his or her message as it takes form, so even very early in the process, the constructed evaluation standards serve as guides (in a positive sense as well) throughout the process. In addition, the evaluation standards are not binary (acceptable versus unacceptable), but rather form a latitude or spectrum of acceptance. A designer imagines what, in reference to Weber (1949), might be called an "ideal-typical banner ad," and when the creation comes close enough to this ideal type, the designer agrees to stop the design process. The standards thus represent benchmarks, but provide arguments and support during the final presentation to the client. This practice can be considered similar to an anticipatory move in the subtle games copywriters play to keep control of their creative work (Kover and Goldberg, 1995). For example, as our respondents acknowledge:

From the first brief of the client onwards, I try to determine what the criteria are on which no compromises can be made: for instance that the brand name has to be very visible. But I also look out for criteria that seem less stringent and on which $I$ can make the client change his mind... . Next, during the creation process itself, I check systematically if my banner corresponds to these criteria.

During the brief I identify already the arguments that I will eventually use to "sell" the banner that I have not even created yet. Of course, the brief orients my creative work, but it also helps to develop my final arguments and to prepare questions to the objections that will be made.

If the evaluation standards are not explicit, the designer imagines them using his or her preliminary experience and representations of the target audience.

During the creative process, the designer also systematically evaluates the aesthetic aspect of the message. Our informants insist that this assessment must be fast, not intellectualized or elaborated; that is, the message must have immediate appeal. When a concept receives a negative evaluation, it might be abandoned or improved during a new round, usually by invoking implicit communication theories ("my message does not attract attention; I need to use an attention grabbing trick"). When it receives a positive evaluation, it gets developed in further detail.

The process of creating the message often ends when the message meets the acceptance criteria of the advertiser, such as the designer imagines them. Therefore, when the designer's imagined voices do not agree, the advertiser's voice dominates and has the last word. The voice of the advertiser therefore enables designers to limit or even erase cognitive dissonance that could cause stress and prevent them from leaving the process of psychic dissociation, which they need to do to generate ideas. Therefore, the concept of "satisficing" (Simon, 1960) applies to web 
The assessment process does not take place only at the end of the creative act. Instead, the designer self-evaluates his or her message as it takes form.

banner production and specifically to the decision-making process involved with stopping the creation process. The copywriter or designer does not systematically seek to create the most influential messages, but rather to create messages whose justification will be accepted by the client. This justification is based on the aesthetic and semiotic techniques that will help the banner advertisement meet its objectives:

Of course, I do all I can to create a banner that generates clickthroughs, but advertising is not a hard science. I am happy when the client is happy.

\section{CONCLUSION AND DISCUSSION}

Despite the growing penetration of broadband internet access that allows for increasingly rich banners, advertising on the internet still consists of relatively simple messages. In addition, internet advertisers often pay more attention to the general format of a banner and media plan than to message creativity, with the goal of getting a high clickthrough rate. We show that the designers of these banners nevertheless take the same mental approach to their creative activity as do advertising copywriters for traditional media, and they appear as personally involved as copywriters (e.g., concerns about self-presentation).

Overall, we replicate Kover's (1995) findings about the existence of implicit theories of communication and the use of internal dialogues with an imaginary audience to enhance message acceptance. The implicit theories elicited from banner designers roughly correspond with those diagnosed by Kover: attract interest and attention and then deliver the message. Some elements are, of course, specific to the internet medium, so for example, acceptance means a clickthrough. We also find elements, like memorization of the message, that Kover does not describe, but that may be relevant for traditional advertising as well. In general, we diagnose mental representations with more dimensions than those described by Kover (1995), and though some additional dimensions may be linked to the specificities of internet advertising, others may be due to the more advanced set of questions we use.

Unlike Kover (1995), we observe multiple dialogues with different imaginary audiences: the internet user, the advertiser, two imaginary colleagues, and the aspirational alter-ego of the designer. In addition, we show how the use of intrapsychic dialogues and implicit theories fit into the overall creative process, as described in existing theories about creativity. A third, more practical difference from Kover's work is our finding that banner designers seem much more concerned than copywriters about the advertiser's evaluation. In our context, the most significant other in the internal dialogues is the advertiser, and getting approval is much more important than it was for copywriters (Kover and Goldberg, 1995), possibly because most banner designers meet their clients personally. In contrast, copywriters rarely interact directly with the advertiser, but rather rely on an account executive to serve as an intermediary. Most banner designers also must personally present and defend their work to the client. Finally and possibly because we find the involvement of five different audiences, unlike Kover's respondents, our informants talk about the compromises they have to make.

We also add two important insights to theories on creative processes. First, evaluations are not restricted to the end phase of the process, but occur throughout. Very early in the creative process, banner designers consider the possible reactions of their imaginary audiences and develop a rationale to get their creative ideas accepted. These simulated reactions, based on a set of evaluation criteria developed early in the design process, often in the form of an ideal-type banner, seem to stimulate creativity and the search for new ideas. Second, banner designers seem more active and deliberate in their search for associations and analogies than creativity theories would suggest. Overall, internal dialogues and evaluations of ideas about and incremental versions of the banners intertwine completely, and the evaluation standards are inseparable from the different imaginary audiences, because each member of a target audience embodies a set of evaluation criteria (Courbet and Fourquet-Courbet, 2005).

We also recognize possible limitations of our study. For example, we interview French banner designers, and though advertising as a business is global, advertising cultures have national dimensions. French advertising, for instance, often aims to entertain the audience with symbolism, humor, and drama (Zandpour, Chang, and Catalano, 1992), whereas American advertising usually focuses on databased arguments about product benefits. Because they try to obtain different types of audience impacts, creative designers from different cultures may operate differently. But it is 
also possible that our findings may transfer to other cultures, because our study describes how implicit theories about communication operate in the form of imaginary dialogues that reveal how idealized others react to incrementally developed messages. Creative persons in different cultures certainly may follow a process with the same structure and form, even if the content of the dialogues and the respective importance of the different partners differ. Examining cultural differences would, in any case, be an interesting topic for further research.

Although banner designers resist formal models and theories of their working methods, our study may help them take a step back and reflect on their personal habits and practice to move their work to a superior level. Most work in isolation and remain rather secretive about their working methods; some may not even realize that there is a method to their work. Understanding how designers work also may help advertisers and account executives develop more productive relationships with them. Finally, we hope this study will be used for the education and training of those involved in communication. Our most surprising result is probably the finding that there exists a creative process for generating convincing messages that is independent of the medium and type of message. That is, banner designers are not that different from creative writers in a traditional advertising world. ABP

Marie-Pierre Fourquet-Courbet (Ph.D.) is an associate professor of communication science at the University of Avignon (France). Her research interests include the influence of the media (television, internet) and of different types of communications (advertising, political communication, olfactive marketing). She also studies the strategies and representations of the communication designers. She has written over 25 articles for scholarly journals or books in commu- nication, marketing, or social psychology and is coauthor of La Télévision et ses Influences (2003, Bruxelles: De Boeck).

Didier Courbet (Ph.D.) is an associate professor of communication science at the University of NiceSophia Antipolis (France). His research interests focus on the psychological processes underlying creativity, implicit measures of advertising persuasiveness, and advertising in a sustainable development context. He has written over 30 articles for scholarly journals or books in marketing communication or social psychology. He is author of Puissance de la Télévision (Paris: L'Harmattan, 1999) and co-author of La Télévision et ses influences (Bruxelles: De Boeck, 2003).

Marc Vanhuele (Ph.D., management, UCLA) is an associate professor of marketing and an associate dean for research at the HEC School of Management, Paris, France. His research focuses on price cognition, CRM, and the effects of ambient advertising.

\section{REFERENCES}

ADAMS, R. www advertising: Advertising and Marketing on the World Wide Web. New York: WatsonGuptill Publications, 2003.

Chandon, J.-L., M. S. Chtourou, and D. R. Fortin. "Effects of Configuration and Exposure Levels on Responses to Web Advertisements." Journal of Advertising Research 43, 2 (2003): 217-29.

Courbet, D., and M.-P. Fourquet-Courbet. "Les processus psychologiques lors de la création publicitaire." Hermès 41 (2005): 67-74.

El-Murad, J., and D. C. West. "The Definition and Measurement of Creativity: What Do We Know?" Journal of Advertising Research 44, 2 (2004): 188-201.

Furnham, A. "Commonsense Theories of Personality." In Everyday Understanding: Social and
Scientific Implication, K. J. Gergen and G. R. Semin, eds. London: Sage, 1990.

Glaser, B. G., and A. L. Strauss. The Discovery of the Grounded Theory: Strategies for Qualitative Research. New York: Adline, 1967.

Johar, G. V., M. B. Holbrook, and B. B. Stern. "The Role of Myth in Creative Advertising Design: Theory, Process, and Outcome," Journal of Advertising 30, 2 (2001): 1-25.

Kirsner, K., C. Speelman, M. Maybery, A. O'Brien-Malone, M. Anderson, and C. MacLeod, eds. Implicit and Explicit Mental Processes. Upper Saddle River, NJ: Lawrence Erlbaum Associates, 1998.

Kover, A. J. “Copywriters' Implicit Theories of Communication: An Exploration." Journal of Consumer Research 21, 4 (1995): 596-611.

- and S. M. Goldberg. "The Games Copywriters Play: Conflict, Quasi-Control, A New Proposal." Journal of Advertising Resenrch 35, 4 (1995): 52-62.

W. M. James, and B. S. Sonner. "To Whom Do Advertising Creatives Write? An Inferential Answer." Journal of Advertising Research 35, 4 (1997): 52-65.

Kris, E. Psychoanalytic Explorations in Art. New York: International University Press, 1952.

Lonergan, D. C., G. M. ScotT, and M. D. Mumford. “Evaluative Aspects of Creative Thought: Effects of Appraisal and Revision Standards." Creativity Research Journal 16, 2\&3 (2004): $231-46$.

Mednick, S. A. "The Associate Basis of the Creative Process." Psychological Revicw 69, 3 (1962): 220-32. 
Mendelsohn, G. A. "Associative and Attentional Processes in Creative Performance." Journal of Personality 44, 2 (1976): 341-69.

Moscovici, S. "The Phenomenon of Social Representations." In Social Representations, R. Farr and S. Moscovici, eds. Cambridge, U.K.: Cambridge University Press, 1984.

Mumford, M. D. "Where Have We Been, Where Are We Going? Taking Stock in Creativity Research." Creativity Research Journal 15, 2\&3 (2003): 107-20.

ReIs, H. T., and S. L. Gable. "Event-Sampling and Other Methods for Studying Everyday Experience." In Handbook of Research Methods in Social and Personality Psychology, $\mathrm{H}$. Reis and C. M. Judd, eds. Cambridge, U.K.: Cambridge University Press, 2000.
Russ, S. W. "Creativity Research: Whither Thou Goest." Creativity Research Journal 15, 2\&3 (2003): 143-45.

Schneider, D. J. “Implicit Personality Theory: A Review." Psychological Bulletin 73, 5 (1973): 294-309.

Simon, H. The New Sciences of Management Decision. New York: Harper and Row, 1960.

SPIGGLE, S. "Analysis and Interpretation of Qualitative Data in Consumer Research." Journal of Consumer Research 21, 3 (1994): 194-203.

SternberG, R. J., and T. I. Lubart. “An Investment Theory of Creativity and its Development." Human Development 34, 1 (1991): 1-23.

Wallas, G. The Art of Thought. New York: Harcourt Brace, 1926.
WEBER, M. The Methodology of the Social Sciences, E. Shils and H. Finch, trans. and eds. New York: The Free Press, 1949.

Weber, R. P. Basic Content Analysis, 2nd ed. Newbury Park, CA: Sage, 1990.

YounG, C. E. "Creative Differences between Copywriters and Art Directors." Journal of Advertising Research 40, 3 (2000): 19-26.

Zandpour, F., C. Chang, and J. Catalano. "Stories, Symbols and Straight Talk: A Comparative Analysis of French, Taiwanese, and U.S. TV Commercials." Journal of Advertising Research 32, 1 (1992): 25-38.

Zefr, R., and B. Aronson. Advertising on the Internet. New York: John Wiley \& Sons, 1999. 


\section{APPENDIX}

\section{Interview Guide}

\section{Introduction to internet advertising}

What are the specificities of internet and banner advertising, compared with advertising in other media? Do the strategic objectives differ? What are the strategies for media planning? What are the links with message creation?

\section{Effects on the receiver}

What is the profile of the average internet user? Why do they surf the internet? How do they react to banners? How is that different from reactions to advertising in other media? What goes on in the mind of the internet user when he or she encounters internet banners? How does advertising on the internet influence its audience? If you forget about what is typically told to advertisers, what do you think are the real effects of internet advertising for products or brands? Up to what point can the client's objectives be met?

\section{Message creation on the internet in}

\section{general}

What are, according to you, the basics of message creation for the internet? What is a good banner? What is a poor banner? Why? For the client, what is a good and what is a poor banner? How do you know? For the internet user, what is a good and what is a poor banner? How do you know? What characterizes a good banner designer?

\section{Creations of the informant}

Overall, what do you try to accomplish? Do you have a creative philosophy you follow? General rules in the way you work? Recurring practices? A personal style? Can you explain this in more detail? How do you think about the internet user? What reactions do you try to obtain? How do you reach this goal?
[At the computer screen, the designer shows some of his or her work.]

Can you show me some banners you have created and explain them to me? [Wait for spontaneous explanations; if none given, continue questioning.] What is the objective of this banner? How did you adapt your creation and the different elements of the message to the communication objectives of the advertiser? What do you think goes on in the internet user's mind from the moment he or she visits the webpage with your banner until the effect that you aim at is obtained? Can you analyze each of the elements of your banner, explain the objective of each, and its effect on the internet user? [If necessary, repeat question about objectives and how they relate to visuals, words, links between text and image, animation, movements, color, shapes, typography, hypertext links, light, interactivity, organization of different elements, etc.]

\section{Protocol: The creation process}

Try to remember the moment you created this banner and put yourself back into that moment. Explain in detail, step by step, how you designed it. You can close your eyes if necessary.

What are the strong and weak points of the banner? Why? How did you "sell" the banner to the advertiser? Which arguments did you develop? How did the advertiser react?

\section{The creation process usually followed}

What is the information that you have in mind right before you start the creation process? Where does this information come from? What do you try to do? Why? Who is the banner aimed at? Who will evaluate it? Do you think about anyone else? When you are creating, what is your way of working? The different steps? How long do they take? Where do the ideas come from? What do you say to yourself during the creation process itself? Tell me in detail. When you feel unable to create a banner or find a solution to a problem you encounter, what do you do? Why?

\section{Protocol: A new creation by the informant}

I would like you to create a banner now. Tell me out loud what you think and what you say to yourself during the process. Do not censure yourself, but also do not add anything that you did not really think or say to yourself. Take your time for this. You can use any material that you usually use.

Are there cases where you say different things? When is that? Why?

\section{Evaluating the banner created}

When do you start seeing if your banner is a good (or poor) one? How exactly do you make this evaluation? What do you look at? Why? What do you say to yourself at that moment? What do you do then? How do you know if the banner will be accepted by your client? How do you know what impact the banner will have on the internet user? In general, what is the interest of designing good banners? Why?

\section{Relationship with the advertiser}

During the first briefing that you receive from the advertiser, what is it you try to know and what information do you receive? How do you present your banners to clients? How do you develop your arguments for the presentation? What are the points you insist on? What do you not talk about? What goes on in your mind at that moment? 
Copyright of Journal of Advertising Research is the property of Cambridge University Press / UK and its content may not be copied or emailed to multiple sites or posted to a listserv without the copyright holder's express written permission. However, users may print, download, or email articles for individual use. 